\title{
Destaques do Parque Industrial de Polímeros do Brasil
}

A Brasilplast'99 estará contando com a participação das mais expressivas empresas ligadas a polímeros no Brasil, nos mais diversos segmentos: fabricantes de matéria-prima, máquinas, equipamentos, resinas, transformadores, etc., além de alguns milhares de visitantes e usuários finais. Essa feira, uma das mais importantes no "ranking" mundial, é um periodo de encontro obrigatório da comunidade brasileira e, a cada edição, mais e mais também de empresas do exterior. Nas páginas que seguem são apresentadas as principais atividades/produtos de 14 empresas conhecidas no país que, apesar de todas as dificuldades do final de 1998 e do início de 1999, brindaram os leitores com informações importantes desses dignos representantes do batalhador parque industrial brasileiro.

Não bastasse a correria de início de ano e o intervalo para o Carnaval em fevereiro, que tanto sobrecarregam os profissionais que devem coordenar os preparativos para a participação de cada uma das empresas na Brasilplast, os brasileiros foram surpreendidos pelo tumulto financeiro provocado pela alta do dólar. A revista "Polímeros: Ciência e Tecnologia" havia convidado a participar desta edição, distribuída também durante a Feira, as mais conhecidas empresas de polímeros do país, abrindo-lhes um espaço para divulgação institucional, de seus produtos, projetos, investimentos, ou seja, para comunicação direta com a comunidade. A correria do final do ano e dos primeiros dois meses de 99 ou não permitiram a participação de muitas delas ou, em alguns casos, apenas a reduziram a uma participação simbólica, com o envio de press- releases. Mesmo com tão pouco prazo para um trabalho efetivo, os resultados são bastante satisfatórios: conseguimos uma série de informações interessantes que, não fosse essa mesma Brasilplast, não estariam sendo divulgadas nesta edição.

\section{$B+2=$ Surpresas na} BRASILPLAST 99

Os negócios de Termoplásticos da BASF no Brasil englobam as áreas de Poliestireno, Poliestireno Expansível, Plásticos de Engenharia, Copolímeros de Estireno, Espuma de Polipropileno e Monoestireno, e os principais mercados de atuação da Unidade são as indústrias automobilísticas, de eletroeletrônicos e de embalagens.

A Unidade registrou um faturamento em 1998 da ordem de US\$
154 milhões, desempenho 59\% superior comparado com o ano anterior. Um dos fatores causadores desse comportamento foi a aquisição do negócio de poliestireno da CBE pela BASF, em agosto de 1997, levando a BASF no Brasil a ocupar a liderança no segmento de poliestireno, com produção nacional e importação.

Outros fatores contribuíram para alavancar a performance da área e entre eles destacam-se o lançamento do primeiro coletor de admissão de gases produzido em plástico (Poliamida) no Brasil, bem como a nova aplicação do Luran ${ }^{\circledR}$ S em tampas de máquinas de lavar roupas. Essa foi a primeira aplicação do ASA desenvolvida na América do Sul no segmento de linha branca, visto que esse produto era somente utilizado na indústria automobilística.

Em 1998 entrou em operação a nova fábrica de espumas de polipro- 


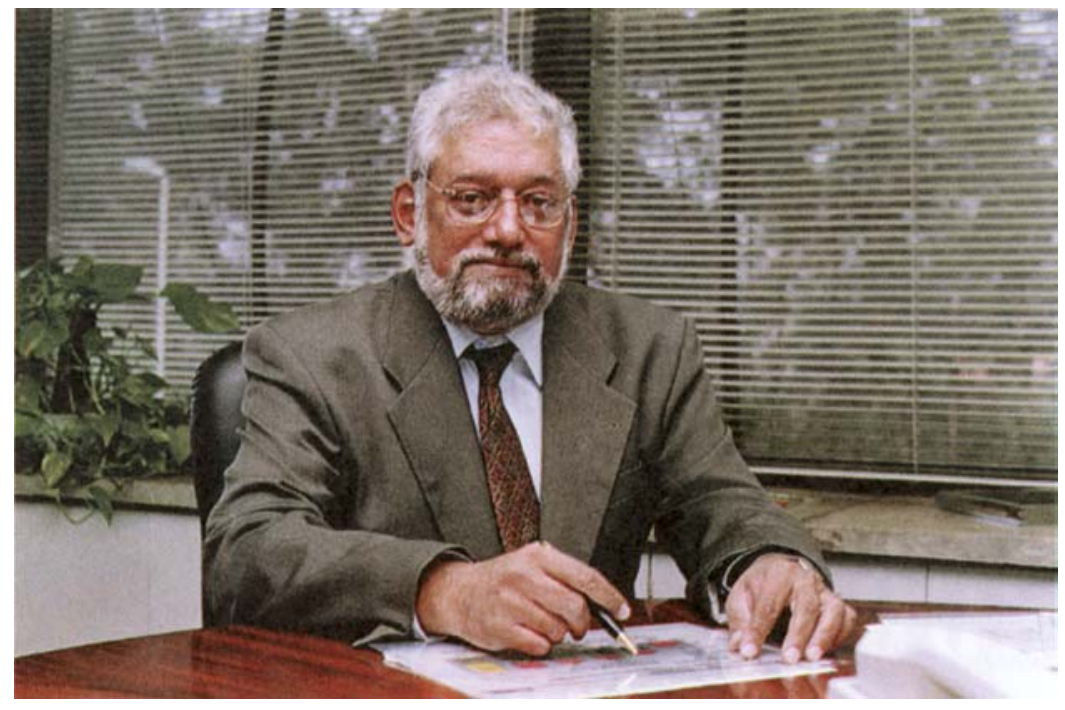

José de Santa Rita Vaz - Diretor da Unidade Regional de Negócios Plásticos da Basf América do Sul

pileno da BASF (Neopolen ( ${ }^{\text {P P) }}$ ) cujas aplicações estão na indústria automobilística, transportes especiais e embalagem. A fábrica é a quarta do gênero no mundo e (as outras estão localizadas nos EUA, Alemanha e Japão) fica no Complexo Químico de Guaratinguetá, onde a BASF investiu cerca de US\$ 5 milhões. Um outro destaque em 98 foi a venda do negócio de Isopor ${ }^{\circledR}$, para se dedicar ao mercado apenas na qualidade de fornecedora de matéria-prima-Styropor ${ }^{\circledR}$. A BASF está expandindo a capacidade produtiva da fábrica de Poliestireno em São José dos Campos, e também da fábrica de Styropor ${ }^{\circledR}$ (Poliestireno Expansível), em Guaratinguetá.

Em 2001, novos investimentos vão imprimir um ritmo ainda mais intenso aos negócios da Unidade. Trata-se da inauguração de duas fábricas, uma de Poliestireno e a outra de Poliestireno Expansível, ambas no Complexo Químico de Guaratinguetá.

O EPS é uma resina utilizada principalmente nas indústrias de embalagens, refrigeração, e construção civil, que nos últimos três anos apresentou expressivo crescimento.
Em 1999, o desempenho para o setor de plásticos não deve ser muito otimista, devido à atual conjuntura econômica do país, desfavorável a muitos setores industriais. Por outro lado, é oportuno considerar que a indústria de plásticos é um dos ramos que possui grande potencial de crescimento no Brasil. Essa constatação é feita com base no consumo per capita em outros países. Para ilustrar esse raciocínio, nos EUA são consumidos $110 \mathrm{~kg} /$ habitante, no Japão $62 \mathrm{~kg} /$ habitante, na Argentina $20 \mathrm{~kg} /$ habitante e no Brasil $15 \mathrm{~kg} / \mathrm{habitante}$ apenas. Esses números revelam o imenso potencial do mercado brasileiro.

Um dos setores que pode impulsionar esse incremento a médio prazo no consumo brasileiro é a indústria automobilística, que está sendo altamente beneficiada pela produção de modelos globais, esperando-se que a curto prazo o consumo específico de plásticos por carro alcance os níveis europeus.

\section{Grupo BASF fornecerá pedaleiras para o Classe $A$}

O Grupo BASF amplia sua atuação no fornecimento de maté- rias-primas plásticas ao mercado brasileiro, apresentando uma inovadora aplicação da Poliamida Ultramid ${ }^{\circledR} A$ na produção do primeiro Bloco de Pedais que equipará o novo modelo compacto da Mercedes, o Classe A. Trata-se de mais uma substituição do Termoplástico de Engenharia em relação à tradicional aplicação do aço, atendendo à constante busca do segmento automobilístico no aperfeiçoamento tecnológico e na otimização dos custos. Certamente, essa nova aplicação, já feita na Europa, deve em breve passar a fazer parte de novo modelos produzidos no Brasil.

A Poliamida 6.6 BASF, cujo nome comercial é Ultramid ${ }^{\circledR}$, será utilizada pela Cofade na injeção do conjunto pedaleira, o qual será parte integrante do sistema de freios do Classe A, feito pela freios Varga. Essa empresa fornecerá o sistema completo, diretamente à nova planta da Mercedes-Benz em Juiz de Fora (MG).

Pioneirismo - com a nova pedaleira, o Grupo BASF dá mais um passo rumo à consolidação de sua linha de termoplástico de engenharia no mercado brasileiro, orgulhando-se de, novamente, ser o primeiro a participar de um projeto inovador automobilístico.

No ano passado, a BASF também participou, com a Filtros Mann e Robert Bosch, do desenvolvimento do primeiro coletor de admissão de gases em Poliamida 6 reforçada (Ultramid ${ }^{\circledR}$ B) do Brasil, aplicado no VW, modelo Gol 1000. No coletor de admissão de gases, a utilização da Poliamida, além de oferecer vantagens de custos em relação ao tradicional alumínio, também contribui para a redução de peso do veículo, aumentando o desempenho do motor. 
Logística - Com o objetivo de melhorar ainda mais a logística do processo, a partir de outubro será criado, em Suzano, um Centro Regional de Distribuição de matérias-primas para plásticos de engenharia. Esse centro será administrado diretamente pela BASF AG. Isso reforça o crescimento desse segmento de mercado, o que num futuro levará a uma produção local. A BASF oferecerá condições comerciais competitivas que garantirão confiabilidade no fornecimento.

\section{BASF lança o Variocrom ${ }^{\circledR}$}

A Unidade de Pigmentos da BASF estará apresentando na Brasilplast'99 sua grande novidade: o primeiro produto da nova linha de "Optically Variable Pigments", cujo nome comercial é Variocrom $\AA$, produto desenvolvido pela BASF na Alemanha que está sendo lançado no Brasil, Estados Unidos e Europa. Trata-se de um pigmento em pó com propriedades ópticas que proporcionam fortes variações de cores, desde vermelhos, violetas e dourados, até verdes, azuis e amarelos, dependendo do ângulo de observação, causadas pelos efeitos de interferência, absorção e reflexão. Este novo produto pode ser utilizado puro ou em combinação com outros pigmentos orgânicos convencionais.

Esta nova alternativa de cores direcionada para o mercado plástico, encontra-se em fase de desenvolvimento, posicionando a BASF como pioneira neste segmento.

Estarão expostas também na feira as tradicionais linhas de pigmentos orgânicos e inorgânicos como Paliogen ${ }^{\circledR}$, Paliotol ${ }^{\circledR}$, Sicotan ${ }^{\circledR}$ e Sicopal ${ }^{\circledR}$, voltados para a produção de masterbatch, e que se destacam pela sua alta performance, excelente resistência, além de abranger ampla gama de tonalidades, já consagradas na Europa.

Outro destaque é a linha de corantes Lumogen ${ }^{\circledR}$, fabricados pela matriz alemã, que apresentam elevada fluorescência quando aplicados em materiais plásticos. $\mathrm{Na}$ oportunidade, serão encontradas as linhas Heliogen ${ }^{\circledR}$ e Sicomin ${ }^{\circledR}$, ambas certificadas pela ISO 9001 e produzidas no Brasil. O Heliogen ${ }^{\circledR}$ é produzido no Complexo Químico de Guaratinguetá, um centro mundial de excelência na produção de ftalocianinas azuis e verdes, que abastece o mercado nacional além de exportar para a Europa e América do Sul.

A BASF consolida mais uma vez, sua destacada posição na indústria de transformação plástica, através da linha de protetores U.V., comercializados sob a forma em pó ou masterbatch, com a marca registrada Uvinul ${ }^{\circledR}$, proveniente da BASF Corporation (Estados Unidos).

Entre as preparações que estarão expostas no estande da BASF durante a Brasilplast, destacam-se as linhas Euthylen ${ }^{\circledR}$, Sicolen ${ }^{\circledR}$, Lufilen $\AA$, Luprofil $₫$ e Sicoplast ${ }^{\circledR}$, para tingimento de diversos polímeros.

\section{BASF Poliuretanos lança tecnologias que eliminam o uso do gás CFC}

A BASF Poliuretano Ltda., empresa do Grupo BASF no Brasil que atua no segmento de sistemas de poliuretano, registrou em 1998 um faturamento superior a 40 milhões de reais e começa 99 com grandes perspectivas de crescimento.

Mesmo conhecida no segmento de calçados, a BASF Poliuretano destaca na Brasilplast'99 os sistemas de poliuretano nas aplicações utilizadas pelas indústrias automobilística, refrigeração, eletroeletrônica e de embalagens, além da indústria de móveis para escritório, mercados nos quais a empresa tem registrado índices expressivos de participação.

Estas aplicações são desenvolvidas com "know how" da BASF, onde os sistemas atualmente comercializados na Europa possuem tecnologia de ponta e possibilitam a eliminação do uso do gás CFC, acompanhando, assim, as regras ambientais mundiais.

\section{Novas tecnologias em sistemas de poliuretano}

A BASF Poliuretano Ltda. levará à Brasilplast'99 novas tecnologias em sistemas de poliuretano que eliminam o uso do gás CFC. $\mathrm{Na}$ oportunidade , serão apresentadas as seguintes novidades para os mercados de:

\section{EletroEletrônicos e Moveleiro}

Caixas para computadores, calculadoras, ventiladores, e ainda, molduras de teto com imitação em gesso são novas aplicações do Elastolit ${ }^{\circledR}$ DR. Este sistema de poliuretano traz em sua composição baixa densidade, as quais podem ser trabalhadas entre 200 a $600 \mathrm{~g} / \mathrm{l}$, além de oferecer boa resistência e dureza elevada.

\section{Automobilístico e Moveleiro}

Peças de espumas flexíveis para a indústria automobilística, e também para o mercado de móveis para escritórios, como cadeiras, são produzidas com o sistema Elastoflex ${ }^{\circledR}$ W. Este produto é à base de água, eliminando o uso do gás CFC. 


\section{Refrigeração}

O sistema Elastopor ${ }^{\circledR}$ R foi desenvolvido especialmente para fabricação de equipamentos e balcões frigoríficos. A espuma obtida com este sistema tem alto teor de células fechadas isentas de agentes CFC.

Além das novidades já citadas, a empresa estará mostrando sua tradicional linha de sistemas de poliuretano para o segmento automobilístico, por meio dos produtos: Elastotherm ${ }^{\circledR} \mathrm{TF}$, dirigido para a aplicação de revestimentos internos de carros. Este produto é uma espuma semi-rígida e de baixa densidade. Elastolit ${ }^{\circledR}$ R, material de alta densidade e com boa resistência à impacto e proteção aos raios ultravioletas. Sua aplicação é destinada quando do encapsulamento dos vidros dos carros ou ônibus. Elastoflex ${ }^{\circledR}$ E, utilizado na fabricação de quebrasol para carros, além de não conter em sua composição o agente expansor CFC, apresenta baixa densidade, aliado a uma boa resistência mecânica. Ainda no mercado automobilístico e moveleiro, temos a linha de sistemas Elastofoam ${ }^{\circledR}$, que foi desenvolvida para a fabricação de peças de espuma de pele integral, aplicados em volantes, alavancas de câmbio e braços de cadeiras para escritório. Esta linha apresenta excelente resistência à abrasão e dependendo de sua aplicação, a densidade pode ser maior ou menor.

\section{BASF apresenta o primeiro regulador de gás em plástico}

Ultramid (PA) e Ultradur (PBT) são os novos plásticos com a marca da BASF que estão inovando o conceito dos reguladores de gases no Brasil. Durante a
Brasilplast'99 a unidade de plásticos da BASF estará apresentando sua grande novidade: o primeiro regulador de gás em plástico no Brasil. Trata-se do desenvolvimento de uma nova aplicação para o Ultramid (Poliamida) e o Ultradur (PBT): um regulador de gás em plástico que substitui os atuais feitos em metal.

O Grupo BASF desenvolveu essa nova aplicação em conjunto com a Agip Liquigás. Características como segurança, custo, peso e durabilidade destacam-se como as principais vantagens do novo regulador, que também é reciclável e não enferruja.

A parceria estabelecida entre a BASF e a Agip Liquigás no desenvolvimento deste projeto para o mercado brasileiro traz o que há de mais inovador na busca de uma solução mais econômica e eficiente.

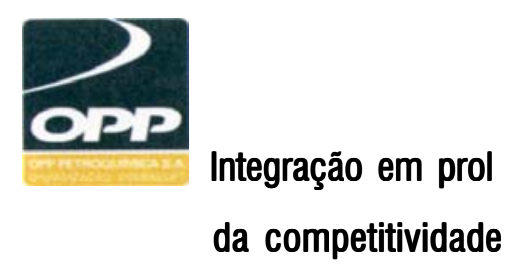

\section{Do sal ao PVC: uma integração chamada Trikem}

A Trikem foi constituída pela integração das empresas CPC Companhia Petroquímica Camaçari, produtora de PVC, e Salgema - Indústrias Químicas, produtora de cloro-soda. A integração ocorreu após a aquisição do controle acionário das duas empresas pela Organização Odebrecht, em 1995, garantindo em uma única empresa todas as fases da cadeia de produção, do sal ao PVC, e foi decisiva para colocar a Trikem dentro dos melhores padrões internacionais de competitividade: aumentou a eficiência, levou ao mercado uma oferta maior de produtos, trouxe ganhos operacionais e redução de custos fixos, acompanhando as tendências da moderna indústria química internacional.

Já consolidada como Trikem, o segundo movimento da empresa foi sua integração operacional com a OPP Petroquímica, no final de 1997, mais um passo para reafirmar as empresas da Odebrecht Química em primeiro lugar no ranking latinoamericano do setor. Além disso, a Trikem detém 16,02\% das ações ordinárias da Norquisa - Nordeste Química (holding que controla a Copene, central de matérias-primas do Pólo Petroquímico do Nordeste, em Camaçari, na Bahia), e tem participações na Rionil, Sansuy e Dacarto, empresas de transformação de PVC e nas centrais de utilidades Cinal, em Alagoas, e Cetrel, na Bahia.

Para a Trikem, ser a número um do ranking em produção, no entanto, não é tudo. Garantindo e expandindo sua fatia de mercado, a empresa oferece apoio aos clientes no desenvolvimento de tecnologias voltadas à utilização das resinas de PVC e de novas aplicações, de acordo com suas necessidades. O trabalho é feito por meio do Centro de Tecnologia e Serviços (CTS), inaugurado em 1987, na unidade industrial da Trikem, em Vila Prudente. Desde fevereiro de 1998, o CTS, que atende em média 100 clientes da Trikem por ano, está baseado na unidade da OPP Petroquímica, em Capuava.

Tecnologia - A evolução tecnológica sempre esteve em pauta na cultura da empresa. Em 1985, a Unidade Piloto de PVC iniciou suas atividades na unidade de PVC de Camaçari, para desenvolvimento de novas resinas e processos. $\mathrm{Na}$ mesma época também foi implan- 


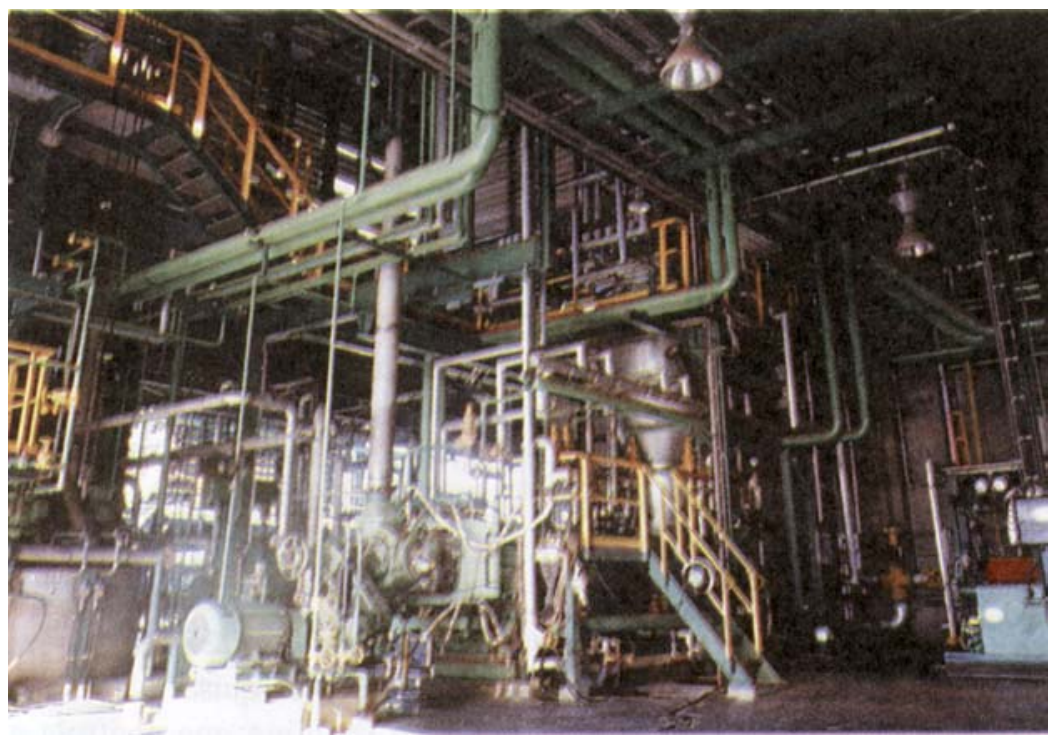

Unidade Industrial da OPP Petroquímica em Capuava - SP

tado o Laboratório de Polimerização, para caracterização dos novos produtos e desenvolvimento de aplicações para o PVC. Entre 1989 e 1995, em Maceió, houve a implantação das unidades piloto Multipropósito (vários produtos derivados de cloro) e Eletroquímica (células-piloto para desenvolvimento de processos de eletrólise), na unidade de cloro-soda.

A transição de CPC e Salgema para Trikem trouxe um novo enfoque à evolução tecnológica da empresa. Antes da fusão e troca de controle acionário, na Salgema a ênfase era dada sobre a diversificação do uso do cloro. Depois de 1995, o foco da Trikem passou a ser sobre o PVC, o MVC e sodacloro, enfatizando o desenvolvimento de processos. Outro fator que elevou a produtividade e reduziu o custo variável das fábricas foi o desenvolvimento e a utilização de novos aditivos na polimerização de PVC.

Ganhos de produção e em qualidade do produto, na Trikem, andam de mãos dadas com a natureza. Ratificando os cuidados da empresa com a preservação do ambiente natural, a ABS Quality
Evaluations recentemente certificou as unidades da Trikem com a ISO 14001. A ABS-QE foi fundada em 1862, em Houston, Texas, e é reconhecida mundialmente junto aos órgãos ANSI-RAB, dos Estados Unidos, RvA, da Holanda, e o brasileiro Inmetro.

Produtos \& Produção - Os avanços tecnológicos permitem que a Trikem esteja, hoje, entre as poucas indústrias do setor no mundo com maior variedade de grades: são 5 tipos de resina suspensão (de maior consumo) e dez de PVC Especialidade. Durante 1999 estão sendo criados dois tipos de PVC suspensão, um para a linha de frascos e conexões, e outro para uso geral em produtos flexíveis e semirígidos, como embalagens, fios e cabos, solado de calçados, perfis rígidos e flexíveis, laminados flexíveis e mangueiras.

Em especialidades, a Trikem vai lançar, ainda no primeiro semestre, uma resina específica para a produção de separadores ou placas que são colocadas no interior das baterias de automóveis. A vantagem oferecida pelo novo produto é a condição de adequado processamento, e por conseguinte melhor qualidade do produto final. Para o segmento de embalagens, está em desenvolvimento uma série de copolímeros especiais para a produção de vernizes litográficos (no Brasil é importado), cuja função é proteger o produto envasado do contato com o metal, por exemplo.

A Trikem possui unidades de PVC em Camaçari (Bahia), Marechal Deodoro (Alagoas) e Vila Prudente (São Paulo), e de cloro-soda em Maceió (AL), além da subsidiária CQR - Companhia Química do Recôncavo, integrada operacionalmente com a unidade de cloro-soda em Camaçari. Em 1998, foram produzidas 440.500 toneladas $(\mathrm{t}) \mathrm{de}$ PVC, 490 mil t de soda cáustica e 478 mil t de EDC. A capacidade nominal para produção de $\mathrm{PVC}$ é de 455 mil t; 520 mil t de soda cáustica e 520 mil t de EDC.

\section{OPP: visão de longo prazo assegura futuro da empresa e do planeta}

Visão de longo prazo. É isto que a OPP Petroquímica leva em conta toda vez que faz seus planos anuais. Neste ano, por exemplo, a empresa já vislumbra resultados para 2001, no que diz respeito ao seu Sistema de Gerenciamento Integrado (SGI). Ou seja, no primeiro ano do próximo milênio, os programas de Qualidade, Saúde, Segurança e Meio Ambiente de todas as suas unidades industriais e da Trikem, além da sede conjunta das duas empresas, em São Paulo, estarão integrados. Na prática, é a integração das certificações ISO 9000, QS 9000 (extensão da ISO 9000, para a indústria automobilística), ISO 14001 e o Programa Atuação Responsável, facilitando a conquista de outras 
certificações importantes, para todo o sistema empresarial.

No dia-a-dia dos clientes da OPP e da Trikem, esta é a garantia de produtos e serviços com melhor qualidade, o que reforça a parceria. E, para as duas empresas, viabiliza ainda mais a prospecção de créditos no exterior, para aumento de produção e atualizações tecnológicas que, por serem cada vez mais limpas, também contribuem para a preservação do ambiente natural - e, enfim, do planeta como um todo.

Será reforçada a participação da Saúde e da Segurança no SGI, neste e no próximo ano. Por meio de benchmarking interno e externo, o Comitê de Excelência em Qualidade, Meio Ambiente, Saúde e Segurança da OPP e da Trikem pretende identificar as melhores práticas, inclusive entre corporações de classe mundial, e implantá-las em toda a empresa. Dessa forma, o objetivo de melhoria contínua no desempenho destas áreas será alcançado, prevêem as duas empresas. A prevenção será o foco principal. No caso da Saúde, serão reforçadas as práticas de higiene ocupacional, o que significa atuar na redução ou eliminação de qualquer risco à saúde das pessoas.

Produção - Alguns dos frutos do planejamento a longo prazo, igualmente, já compõem o presente da maior produtora de resinas termoplásticas da América Latina, com capacidade nominal de 1,139 milhão de toneladas ( $\mathrm{t}$ ) ao ano, na soma de commodities e especialidades. No ano passado, foram produzidas 507 mil t de polietileno (PE), 407 mil t de polipropileno (PP) e 52 mil t de especialidades.

A partir de julho, entra em operação mais uma unidade industrial da OPP, no Pólo Petroquímico de

Triunfo. Com tecnologia Spherilene, a nova fábrica terá capacidade nominal para produzir $260 \mathrm{mil}$ t/ano da resina PE quarter polímero (copolímero com quatro elementos), adaptada às necessidades do mercado brasileiro, para a produção de filmes de embalagens de alimentos. A evolução tecnológica e o progressivo aumento da produção sempre estão nos planos da empresa.

Desde 1979, quando a Organização Odebrecht, por meio da Odebrecht Química, passou a participar do setor petroquímico, seu

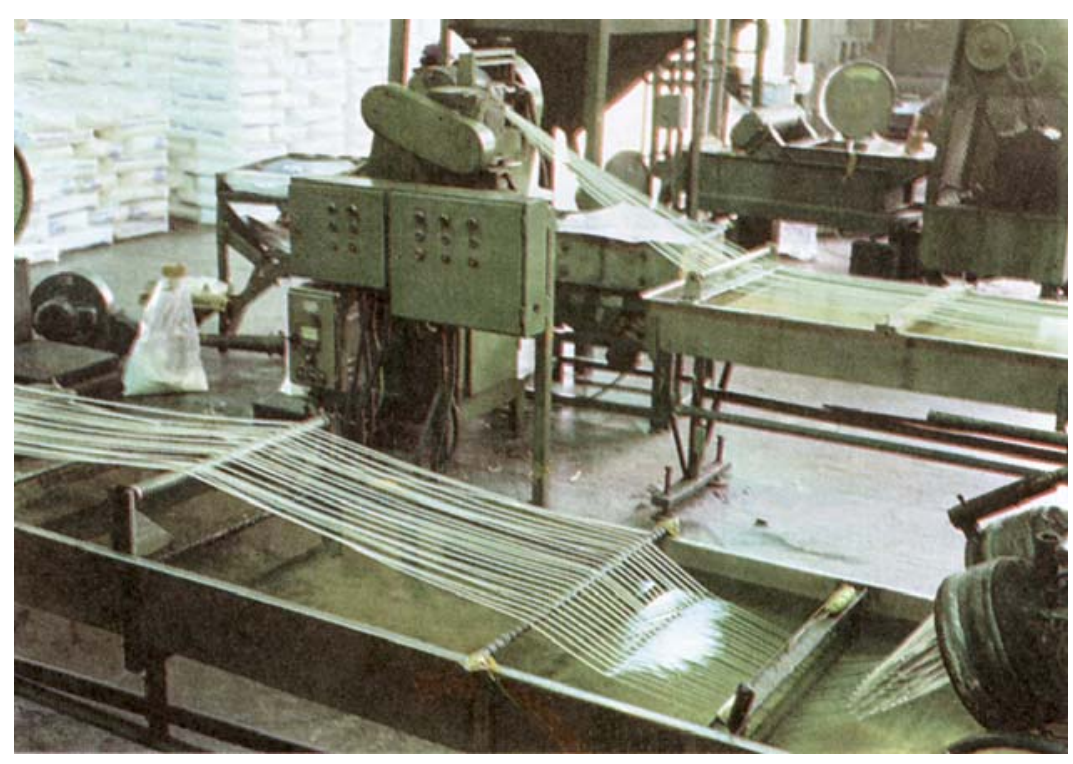

Unidade Industrial da OPP Petroquímica em Triunfo - RS

raio de ação foi planejado para a constante expansão. Em 1997, a OPP ampliou sua produção de 749 mil t/ano para 852,9 mil t/ano; em 1998, para 1,139 milhão t/ano; e, ao final deste ano, para 1,400 milhão t/ano, fato que consolida sua posição como número um no ranking latino-americano do setor.

Tecnologia - Com integrantes qualificados, reconhecidos inclusive por empresas internacionais, a capacidade tecnológica da OPP vai muito além dos portões da fábrica. Em 1997, uma equipe de técnicos da OPP foi convidada a colocar em operação uma unidade industrial de polipropileno com tecnologia Spheripol, na empresa espanhola Repsol. A escola dos convidados brasileiros é a própria OPP que, se por um lado, importa tecnologia, logo aprende a lidar com ela, para avançar muito mais do que simplesmente operá-la perfeitamente. No mesmo ano, por exemplo, foi implantada a segunda unidade de PP Spheripol com engenharia básica própria, incorporando melhorias que permitiram o aumento de produção, a redução dos custos variáveis e a produção de resinas de PP diferenciadas. No ano passado, foi desenvolvido um sistema catalítico para uso na unidade Slurry (PP), e o Sistema de Reação Dual na unidade Alta Pressão (PE), avanços tecnológicos que também resultaram em incremento de produção e redução do custo variável, além da diferenciação de produtos.

Para este ano, estão em pauta o início da operação da unidade Spherilene e a expansão da tecnologia APC (Advanced Process Control ou Controle Avançado de Processo) na unidade Unipol - essa tecnologia já foi implantada com 
sucesso em uma unidade Spheripol. O objetivo do APC é gerar economia e melhorar ainda mais a qualidade do produto à medida que a

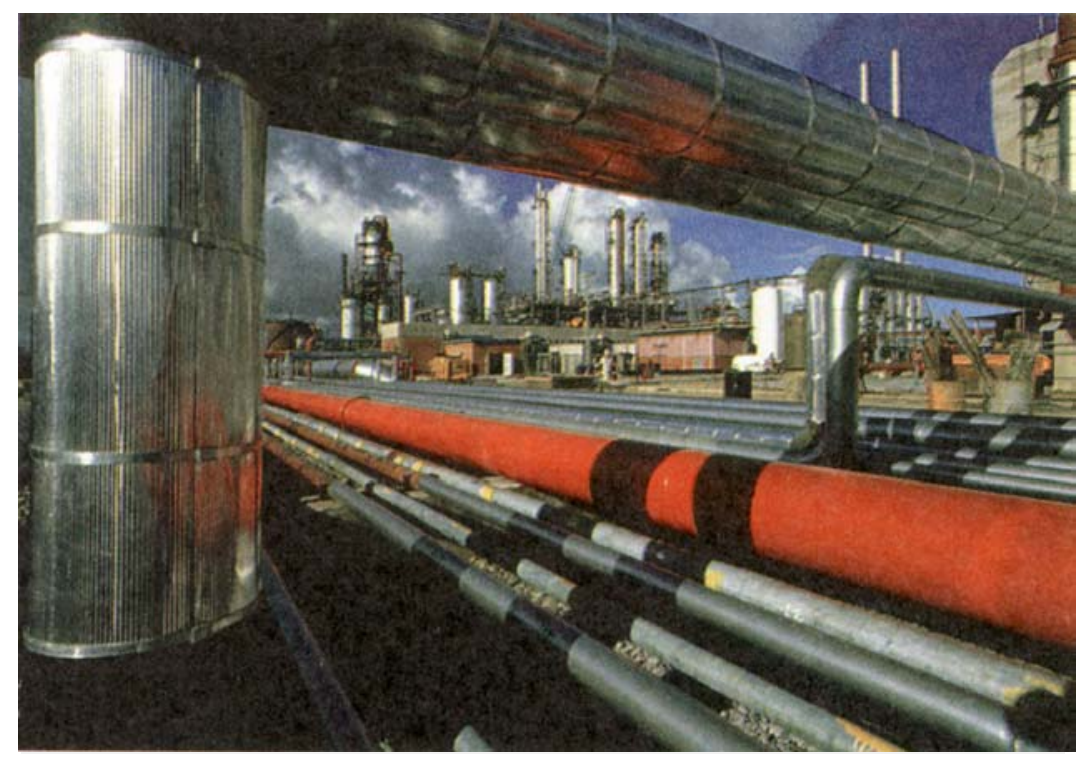

Unidade Industrial da Trikem em Alagoas

capacidade de produção das unidades é aumentada e a produção de resinas não conformes é reduzida ao máximo. As metas de um futuro próximo são o desenvolvimento de processos produtivos; modificações físicas e químicas de polímeros pós-reator (isto é, após ter sido produzido no reator), para uso em bens de produto final com características especiais como melhores propriedades mecânicas (maior resistência ao impacto, peso), ou adesividade de tintas; e a expansão da tecnologia APC para outras unidades industriais.

Preservação ambiental - Em parceria com a comunidade, por meio de programas como Formando Laços, visitas dos moradores próximos das fábricas ao interior das unidades industriais e as campanhas de educação ambiental, durante o verão, Operação Praia Limpa e Promoção Arte na Praia, a OPP mostra sua atuação social e de

preservação do ambiente natural dentro e fora de suas áreas industriais. E é benchmarking para as outras empresas do setor, tanto em

\section{Saiba mais sobre a OPP e a Trikem, na}

\section{Brasilplast}

Como em 1997, nesta edição a OPP e a Trikem estarão juntas, no mesmo estande da Brasilplast. Com aproximadamente 450 metros quadrados, às ruas C-50 e D-51, no estande serão lançadas as resinas termoplásticas de última geração da OPP, enquanto a Trikem distribuirá a versão em CD-ROM do Manual de Produtos de PVC na Construção Civil. Além disso, o local contemplará informações gerais sobre as duas empresas, como suas ações em conjunto com a comunidade e os programas para a preservação do ambiente natural. qualidade dos produtos (todos os processos de produção possuem a ISO 9000) quanto na conquista da ISO 14001, pois a OPP foi a primeira indústria do setor no Brasil a certificar todas as suas unidades, em 1996.

Para educar, não há nada mais eficiente do que o bom exemplo. Também foi assim quando a OPP lançou as campanhas de verão, iniciadas no litoral do Rio Grande do Sul, há quatro anos, e depois ampliadas para São Paulo, Bahia e Alagoas. A distribuição de sacolas plásticas para acondicionar o lixo gerado à beira-mar, seguida por instruções de monitores sobre como manter a praia limpa para o bem de todos, e o envolvimento de educadores e artistas plásticos com a educação de crianças para a reciclagem de objetos de plástico descartável, que se transformam em brinquedos ou utilidades, já alcançaram mais de 20 milhões de pessoas. Mais uma evidência de preocupação com o futuro, não só da empresa, mas de todo o planeta.

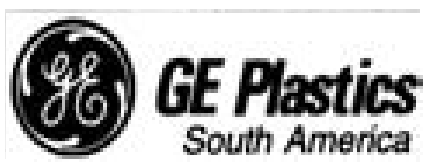

\section{Presença marcante da GE}

Maior fornecedora de plásticos de engenharia para a América do Sul, a GE Plastics South America estará marcando presença na Brasilplast'99, apresentando as últimas novidades mundiais em produtos desenvolvidos com a mais variada escala de cores, excepcional brilho e resistência, resultado de sua avançada tecnologia e experiência combinadas com as atualizadas exigências do mercado internacional. 
No período de 8 a 13 de março poderão vistas pela primeira vez no Brasil, especialmente importadas para a feira, algumas partes e componentes do novíssimo Beetle (Fusca), feitos do termoplástico Noryl GTX ${ }^{\circledR}$, resultante de uma blenda de PPO\&PA. Dentro do marketing automotivo, estarão sendo exibidos também um carro Scénic, o mais recente lançamento da Renault, e um Golf, da Volkswagen, ambos com partes e componentes à base de Noryl ${ }^{\circledR}$ (mod. PPO resin), além dos módulos da carroceria do surpreendente Smart, a mais nova sensação da indústria automotiva alemã, cujo exterior é todo produzido com Xenoy®, uma liga especial de PC e PBT.

A GE Plastics mostrará também alguns produtos e peças que vêm repercutindo internacionalmente pela beleza e pelos padrões de praticidade e funcionalidade atualmente exigidos. De aparência e brilho semelhantes aos melhores mármores e metais, a resina Cycolac Magix ${ }^{\circledR}(\mathrm{ABS})$ certamente será uma das grandes novidades da Feira, através da mostra de um novíssimo aspirador fabricado pela Philips. Quanto a uma outra resina, o Enduran ${ }^{\circledR}$ (Min. Filled PBT), a simples observação de algumas peças fabricadas com esse produto comprova a razão de ser considerado como o de maior índice de crescimento na fabricação de equipamentos para cozinhas e banheiros.

Destacando-se também entre os produtos da GE Plastics está o Lexan ${ }^{\circledR}$, um dos mais consagrados produtos da empresa a nível internacional, largamente utilizado nos micro-computadores "Mac" da Apple pela beleza e transparência das cores. Outras resinas como Cycoloy ${ }^{\circledR}$ (liga de PC\&ABS),
Gelon ${ }^{\circledR}$ (poliamida de alta qualidade), Valox ${ }^{\circledR}$ (PBT), Ultem ${ }^{\circledR}$ (PEI) e Azdel ${ }^{\circledR}$ (o composto termoplástico mais utilizado para produtos estruturais) terão lugar de destaque no estande da GE Plastics - ruas E (10) e F (11) - onde vários engenheiros e técnicos estarão "full time" à disposição dos visitantes.

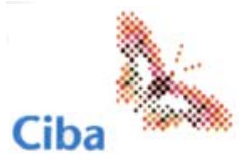

\section{Apresentando novos produtos}

A Ciba Especialidades Químicas - Additives, líder mundial na fabricação de Aditivos, marca sua presença na Brasilplast, oferecendo produtos e tecnologia de ponta para agregar valor aos polímeros.

Os novos produtos de sua linha melhoram a aparência e a performance dos polímeros, garantindo melhores resultados para a indústria de produção, transformação e seus consumidores finais. Estes resultados aparecem nas mais diversas situações de nossa vida, desde embalagens de alimentos até componentes da indústria automobilística.

\section{Produtos:}

- CHIMASSORB ${ }^{\circledR e}$ TINUVIN $^{\circledR}$

- Estabilizantes à luz - prolongam a vida útil dos produtos acabados durante sua exposição à luz ultra violeta.

- IRGACLEAR ${ }^{\circledR}$ - Agentes clarificantes

- IRGAFOS ${ }^{\circledR}$ - Co- Estabilizantes que aumentam a eficiência da antioxidação no processo - IRGANOX ${ }^{\circledR}$ - Antioxidantes que aumentam a vida útil e a es- tabilidade térmica de produtos acabados

- IRGANOX ${ }^{\circledR}$ B-blend - Misturas de antioxidantes e co-estabilizantes

- IRGASAN ${ }^{\circledR}$ - Agente Antimicrobiano

- PolyAd ${ }^{\circledR}$ - Misturas de aditivos multifuncionais

- UVITEX ${ }^{\circledR}$ - Branqueadores óticos

- ATMER ${ }^{\circledR(1)}$ - Agentes antiestático e antifoging.

(1) Marca Registrada da ICI Industrial Chemicals

\section{EJSENGARO \\ Semeraro reforça parceria em sopro}

Empresa em constante evolução, sintonizada com a atualização exigida pela globalização, a Semeraro acaba de se reestruturar para tornar-se mais competitiva. A empresa continua sua parceria com a Sandretto do Brasil na industrialização de injetoras, mas ampliou seu portfolio, consolidando um de seus pontos fortes: a fabricação e comercialização de máquinas sopradoras. Com a aquisição da Uniloy pela Milacron, um dos líderes mundiais em tecnologia para máquinas de transformação, a Semeraro formou uma parceria internacional voltada unicamente para a indústria do plástico, o que vai lhe garantir, entre outros benefícios, a produção da maior gama de máquinas sopradoras do mundo.

Além do respeito que sempre demonstrou por seus clientes e da qualidade dos produtos oferecidos, a Semeraro vem provar também que o parque industrial brasileiro tem a competência e a visão de futuro necessárias para participar desse mercado globalizado. 


\section{Rhodia-ster}

\section{Rhodia-Ster mostra novidades em aplicações de resina}

Líder no mercado no fornecimento de resina, a Rhodia-Ster está na Brasilplast apresentando, entre outras novidades, a utilização de suas resinas Rhopet em aplicações inovadoras para as indústrias de embalagens de água mineral, cosméticos e farmacêuticos, óleo comestível, bebidas carbonatadas, sucos, destilados e diversos alimentos, produtos de limpeza e domésticos, entre outros.

No estande da empresa, à rua $\mathrm{D}$ 10/E 11, será apresentada a nova linha de escovas de dentes fabricadas pela PHB Sanifill utilizando Rhopet: as escovas são mais bonitas, mais transparentes e têm custo final $20 \%$ menor do que as produzidas em ABS. Além do preço competitivo e maior resistência, outro diferencial desse produto é a não-toxidade do material empregado. Outras novidades são os cabides de roupas, canetas e outros produtos que, por serem fabricados com resinas da linha Rhopet, apresentam mais resistência, transparência, resultando em custos mais competitivos para os clientes.

A Rhodia-Ster estará oferecendo a seus clientes a oportunidade de conhecerem melhor os processos de pesquisa e desenvolvimento de embalagens, com a apresentação de modernos sistemas de CAD/ $\mathrm{CAE}$, que mostram o produto em diversas fases, desde a realização do projeto tridimensional na tela do computador ou em estágios mais avançados, através de protótipos em resina maciça ou oca. Um dos projetos mais interessantes, lançado em 1998, é a embalagem do molho para saladas Helmann's, desenvolvido em parceria com as Refinações de Milho Brasil.

Durante a Brasilplast 99 estarão sendo divulgadas também as soluções de logística que a Rhodia-Ster vem adotando para garantir, dentro e fora do Brasil, a entre-

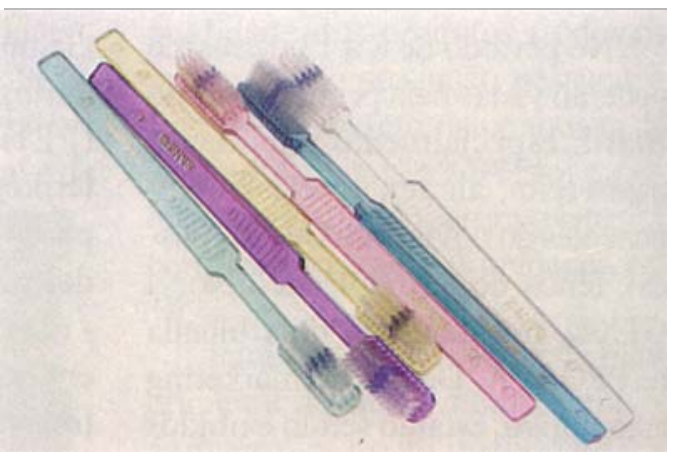

Escovas de dentes em resina Rhopet ga de resina PET com muito mais rapidez e segurança, e a custos mais reduzidos. Uma dessas soluções é o transporte do PET a granel que agrega vantagens e elimina desperdícios de tempo e de mão-de-obra. Pelo sistema a granel, a manipulação do PET praticamente não existe. O PET é injetado por sistema pneumático ou gravidade em uma grande e única embalagem de poliéster altamente resistente e asséptica (liner) já previamente instalada dentro do container, que acondiciona 21 toneladas do produto. Após a carga, o liner é lacrado, o que mantém o produto limpo e seco, garantindo a máxima preservação de suas características.

\section{UNIROYAL \\ QUÍMICA A mais alta tecnologia em extrusoras de borracha}

Presente no Brasil desde o início da década de 70, a Uniroyal Química mantém, em Rio Claro (SP) uma unidade responsável pela produção de aditivos de proteção para borracha (anti-ozonantes e anti-oxidantes amínicos); resinas de poliuretano curável do tipo fundido de alta performance; defensivos agrícolas como antibrotantes, tratamento de semente e acaricidas para laranja. Seu mercado de atuação é bastante abrangente, aten- dendo necessidades, entre outras, da indústria pneumática, de mineração e siderurgia, através da protécnicos de borracha e de plástico de engenharia; óleos lubrificantes, revestimento de tubulações, rotores, etc.

Subsidiária do grupo Crompton \& Knowles - USA, a Uniroyal Química conseguiu um grande trunfo no mercado brasileiro ao comercializar para a indústria de borracha máquinas e sistemas produzidos por outra divisão da Crompton \& Knowles, a DavisStandard Co., detentora de $90 \%$ do mercado total de equipamentos para processamento de borracha nos Estados Unidos. Tão expressivo percentual conta com o concurso de outras empresas do grupo como as americanas Sterling FHB Harting, NRM Extrusion, Killion Extruders. Ressalte-se, também a expressiva participação no mercado europeu da Davis-Standard

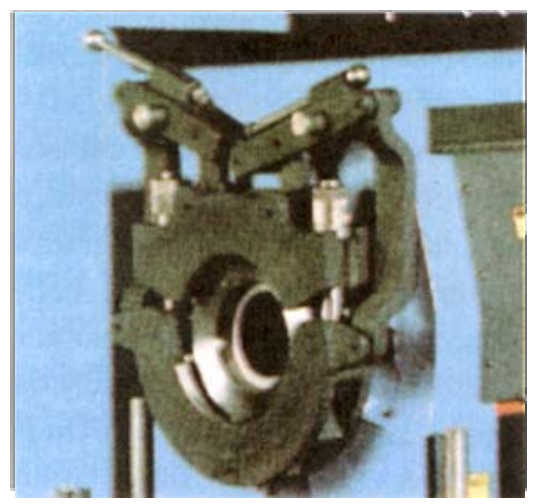

Desconexão de abertura rápida dução de polímeros, artefatos 


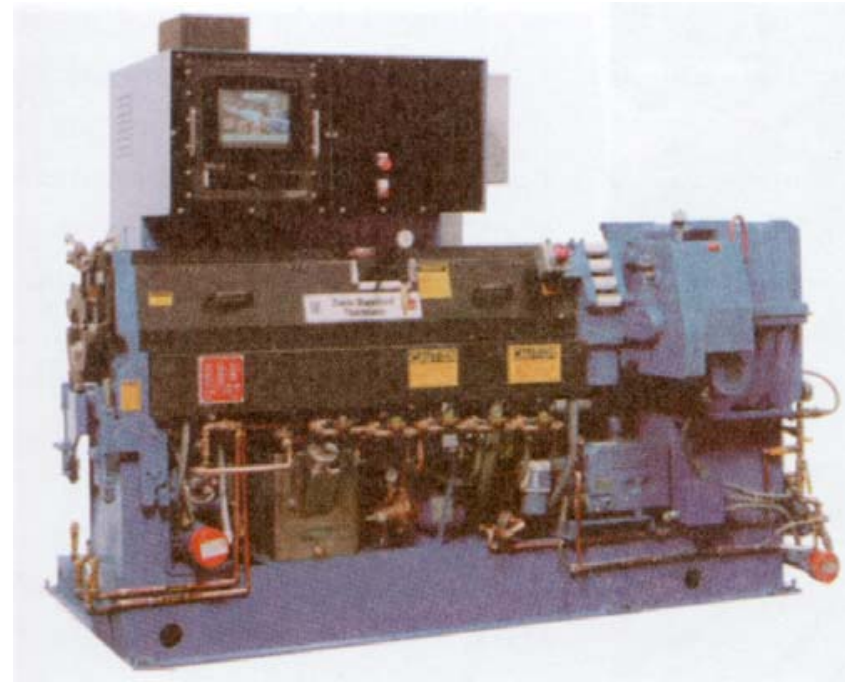

Extrusoras Multiuso de Borracha

France e ER-WE-PA, na França e Alemanha, respectivamente.

O domínio da Davis-Standard no território americano é resultante do fato de há mais de 50 anos a empresa ser o referencial para o sistema de extrusão da borracha, através do qual são avaliadas as demais empresas do setor. Justifica-se sua presença em todo o mundo como "a melhor companhia oferecendo a melhor máquina". Sua área de atuação é muito abrangente, na medida em que trabalha com sistemas completos para fios e cabos, filmes (sopro, fundição e extrusão), injeção, co-extrusão, compounding, reciclagem, elastômeros; extrusoras para fibras, pneus, tubos e perfis.

Além de robustos e versáteis, os produtos da Davis-Std. contam com

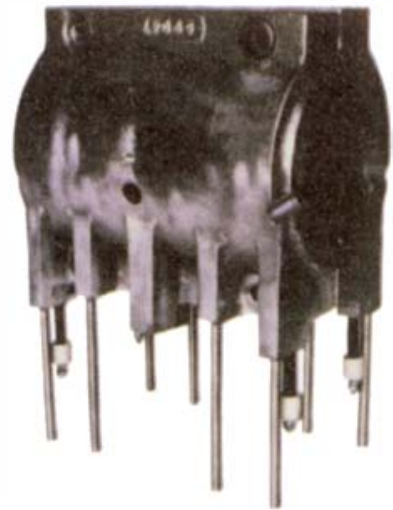

Sistema de Aquecimento/Resfriamento ultrarápido. uma série de pontos fortes realmente imbatíveis, tanto pela alta tec nologia envolvida no processo (por exemplo, no design e configuração de roscas simples ou duplas, cabeçotes planos e transversais, canhões lisos e pinados); como pela excelência dos serviços oferecidos, como upgrade de todo tipo de extrusora e assistência on-line com especialistas treinados em centros técnicos especializados. Seguem dados característicos da extrusora de borracha e multipropósito, top de linha da empresa:

- operação totalmente automatizada através do sistema EPIC II ${ }^{\mathrm{TM}}$ (Extrusion Processor Intelligent Control), que incorpora as mais recentes tecnologias de CPU de alta velocidade, gráficos de alta resolução, tecnologia de tela sensível ao toque de última geração e avançada concepção de CLP;

- sistema de aquecimento e resfriamento com controle de temperatura do produto e não do líquido refrigerante, através de eficientes aquecedores/resfriadores, fundidos em alumínio, bi-partidos pelo método de parafuso e anel, que mantêm um íntimo contato com o canhão em todas as temperaturas;

- exclusivo sistema de alimentação que regula a velocidade do rolo através de um sensor de torque controlado pneumaticamente, acionado por um mecanismo completamente independente do eixo principal, e que compensa automaticamente as variações dimensionais da tira de alimentação; - desconexão de abertura rápida, com parafusos pivotados duplos que permitem fixação simétrica e uniforme ao abrir os flanges cônicos, assegurando um perfeito alinhamento e vedação do cabeçote de extrusão;

- caixa de engrenagem de alta qualidade, com melhor capacidade térmica, de longa vida útil e de operação silenciosa.

Maiores informações sobre a linha de produtos da Davis-Standard podem ser obtidas diretamente com a Uniroyal Química * ou em seu estande na Brasilplast onde os visitantes poderão também conhecer a extrusora de borracha de canhão liso especialmente importada para a Feira.

*Av. Eng. Luís Carlos Berrini, $1297-11^{\circ}$ and., CEP 04571-010, São Paulo/SP, tel (011) 5506-3611, fax 5506-3955.

\section{Ipiranga}

\section{Ipiranga Petroquímica: investimento em novos produtos e novas plantas}

A Ipiranga Petroquímica, maior produtora de Polietileno de Alta Densidade (PEAD) da América Latina, colocará em operação três novas unidades produtivas em 1999. Com recursos externos já garantidos, a IPQ irá passar de uma capacidade de produção de 350.000 t/ano para $750.000 t / a n o$ de produtos petroquímicos. Esta ampliação possibilitará uma diversificação de sua produção com a oferta de dois novos produtos: Polietileno de Baixa 


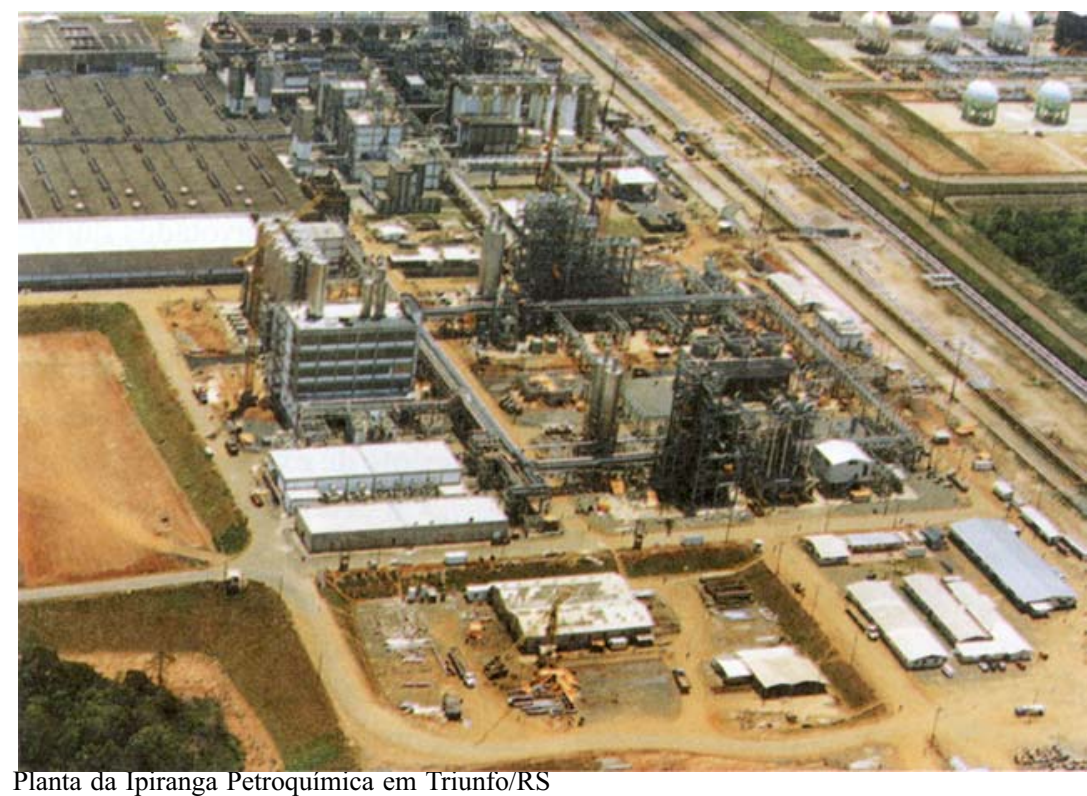

Densidade Linear (PEBDL) e Polipropileno (PP). Uma das plantas, com tecnologia Spheripol (Montell), produzirá 150.000t/ano de PP, irá iniciar suas operações em maio/99. A outra planta, com tecnologia Spherilene, ofertará 150.000t/ano de PEAD/PEBDL (planta "swing") e o começo das operações está marcado para junho/99. Esta unidade será a primeira em operação na América Latina com tecnologia Spherilene, uma das mais avançadas em produção de PEAD/PEBDL.

Estas duas novas plantas estarão localizadas no mesmo "site" (Pólo Petroquímico de Triunfo), junto com as outras três plantas de PEAD que a companhia possui atualmente. Já a terceira faz parte de uma associação com empresas privadas chilenas. Esta unidade, localizada em Talcahuano (Chile), produzirá 100.000t/ano de PP a partir do $3^{\circ}$ trimestre de 99 e faz parte da estratégia da empresa de se tornar uma "regional player".

Como parte de sua política de vendas, a Ipiranga Petroquímica mantém exportações regulares para a América Latina, perfazendo aproximadamente $25 \%$ das vendas totais. Seus dois principais mercados são Argentina e Chile, onde a empresa possui filiais para melhor atender à demanda de seus clientes externos. Desta forma, a empresa pretende consolidar sua posição de líder em PEAD no Mercosul, acreditando ser esta uma região de grande crescimento em potencial, devido, principalmente, ao seu baixo consumo per capita quando comparado a outras regiões de mesmo desenvolvimento econômico.

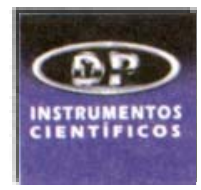

\section{Tecnologia de ponta em analisado- res térmicos simultâneos}

Especialista em análise térmica, a DP Instrumentos Científicos Ltda. tem uma experiência de 10 anos comercializando módulos como DSC, TMA, TGA modulado, análises dinâmico-mecânicas RSA DMTA, testes de tensão e de- formação, viscosímetros e reômetros (incluindo os de extrusão capilar).

Entrevistado por "Polímeros: Ciência e Tecnologia", Carlos Braga, diretor da DP, não escondeu seu entusiasmo com o novo equipamento comercializado pela empresa, a série STA de analisadores térmicos simultâneos fabricados pela Rheometric Scientific. Com módulo e softwares aprovados pela ASTM, o novo equipamento traz a mais avançada tecnologia para a realização simultânea de análises DSC/ TGA/DTA, com incomparável ganho de tempo e confiabilidade de resultados. Muitas são as vezes em que os valores de entalpia em DSC convencionais não são repetitivos, pela falta de consideração da perda de massa durante o processo de aquecimento (água, voláteis, etc) ou pela desigualdade nos tempos obtidos em estudos de tempo de estabilidade oxidativa, devido ao enorme volume de gás existente nas mangueiras e acessórios de chaveamento de gases. Estas situações agora são facilmente resolvidas com o STA, módulo avançado para análise térmica produzido pela empresa norte-americana Rheometrics Scientific. O equipamento permite realizar simultaneamente, em uma única amostra, análises termogravimétricas (perda de massa), análises quantitativas de varredura de calorimetria diferencial e análises DTA.

A balança TGA é montada em mecanismo verticalmente orientado, possibilitando análises em alta resolução, enquanto o prato de fluxo de calor permite análises quantitativas de DSC com alta sensibilidade, incluindo análises 


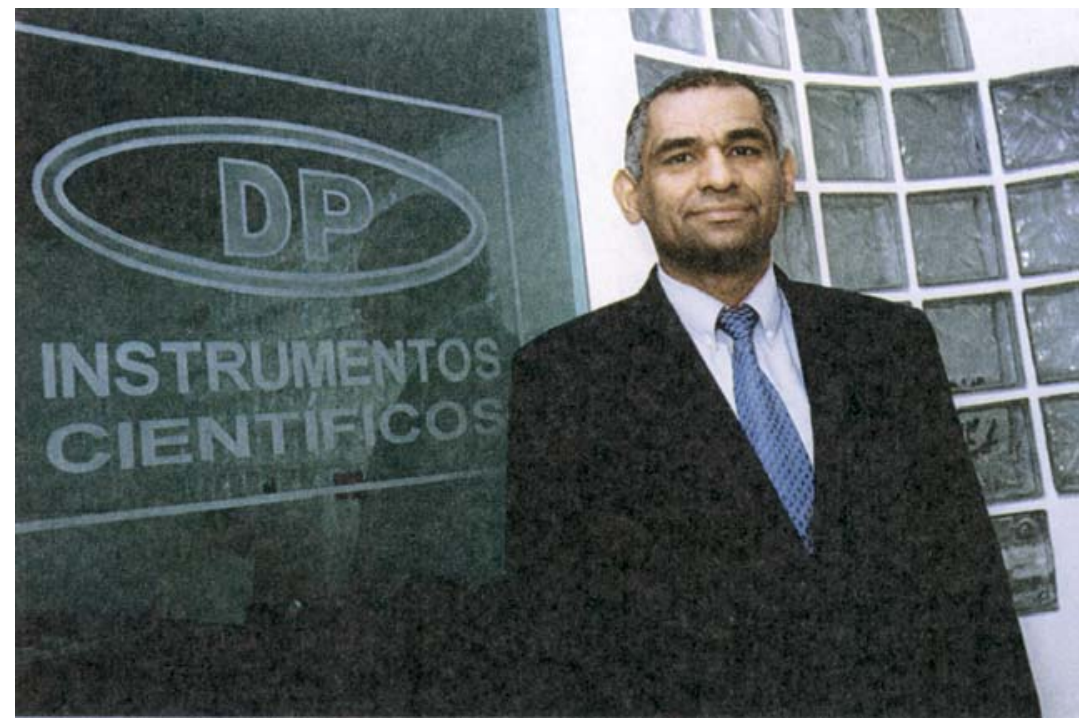

Carlos I. Braga - Sócio Diretor da DP Instrumentos Científicos Ltda.

DTA (análises de diferencial de temperatura). Inclui ainda uma cabeça de medição que facilmente poderá ser expandida para trabalho em análises de gases desprendidos através de técnicas acopladas (EGA). Todo o sistema de análise térmica DSC/TGA/DTA é controlado através de software dedicado, exclusivamente desenvolvido pela Microsoft para utilização nos sistemas de análise térmica e reologia da Rheometrics, possibilitando análise de dados, calibrações, criação de métodos, autodiagnóstico, conexão em rede de dados, servidores, etc, dentro do ambiente Windows 95/ 98 Microsoft. Os sistemas avançados de análise térmica permitem que o software operacional seja instalado em qualquer computador convencional compatível IBM, minimizando o custo de peças para reparo, facilitando a substituição rápida e eficiente por computadores mais modernos sempre que a relação custo-benefício for interessante.

$O$ equipamento não apenas possibilita a realização de análise DTA/TGA como as de DSC, acrescentando, entre outras, as seguin- tes vantagens e possibilidades:

- Controle automático de gases de purga ("built in") dentro do próprio módulo, alterando a atmosfera sem necessidade de intervenção do operador, possibilitando a verificação de estabilidade oxidativa OIT, alteração da explosividade com a atmosfera, envelhecimento. O comutador de gás utilizado permite sensível redução no tempo de troca dos gases, o que é um benefício considerável uma vez que o tempo médio para a completa substituição de um gás por outro em um determinado volume é de aproximadamente dez vezes o volume dividido pela vazão de trabalho.

- Medição direta do fluxo de gás através de flowmeter incorporado aos módulos DSC, TGA e DTA, permitindo um monitoramento contínuo.

- Resultado do fluxo de calor, DTA e perda de massa em função da temperatura ou do tempo. - Opção de aquisição de panelas de amostra com diferentes profundidades, facilitando os trabalhos com amostras de baixa densidade.
- As análises de TGA em alta resolução permitem visualização da perda de massa associada às transições do módulo DSC em uma única amostra.

- Operação de temperatura entre -125 a $1500^{\circ} \mathrm{C}$ (DSC/TGA/DTA) e até $1640^{\circ} \mathrm{C}$ para TGA/DTA.

- Capacidade máxima da balança de até 3,5 gramas.

- Tecnologia atual que permite conectar vários módulos a um mesmo computador para operação simultânea, utilizando apenas uma placa serial.

- Custo mínimo na reposição da célula, em torno de $40 \%$ do preços dos equipamentos com tecnologia tradicionais.

- Facilidade do ambiente Windows 95/98 Microsoft, permitindo conexão de várias saídas de dados, impressoras, plotters, laser e interligação com vários softwares.

Ao realizar análises DSC, o módulo permite conhecer: os resultados dos estudos de reações exotérmicas e endotérmicas; temperatura de transição vítrea $(\mathrm{Tg})$; capacidade térmica; pureza; grau de cristalinidade; temperatura de fusão; temperatura de cristalização; entalpia de reação; entalpia de transição; ponto de ebulição; estabilidade oxidativa; reações, taxa e grau de cura; reações e estudos cinéticos; estabilidade térmica; calor específico; atmosfera controlada; grandezas em gráficos ou tabelas em função da temperatura ou do tempo. Nas análises TGA pode-se ter resultados de variação da massa em função da temperatura ou tempo, mantendo a atmosfera controlada.

A comercialização do analisador térmico simultâneo (STA) da Rheometric vem, assim, disponi- 
bilizar para a comunidade equipamentos de última geração, com excelente relação custo/benefício, versatilidade e produtividade. Segundo Braga, além do novo equipamento, a DP Instrumentos iniciou em dezembro último um novo serviço à comunidade realizando, junto com a Rheometric,testes interlaboratoriais de DMTA. Estão sendo preparados também cursos de análise térmica com especialistas na técnica, para oferecimento aos usuários no $2^{\circ}$ semestre de 99, prática essa corrente nos Estados Unidos, onde já estão disponíveis os cursos de DSC/TGA/DTA, DMTA/RSA, Reologia, Reologia Avançada e Stress Rheometer.

\section{DSM}

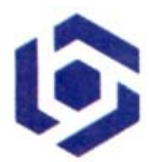

DSM - ampliando área de atuação

A partir de $1^{\circ}$ de janeiro de 1999, a DSM está operando uma nova empresa na América do sul: DSM South America Ltda. Esta nova empresa está trazendo quatro novos negócios: plásticos de engenharia, compostos de polipropileno, borrachas termoplásticas e resinas em pó para tintas.

\section{Rhodia}

\section{Novidades da Rhodia Engineering Plastics}

Uma série de novidades em produtos para a indústria automobilística e uma inédita linha para aplicações em peças feitas pela indústria de eletroeletrônicos e ele-

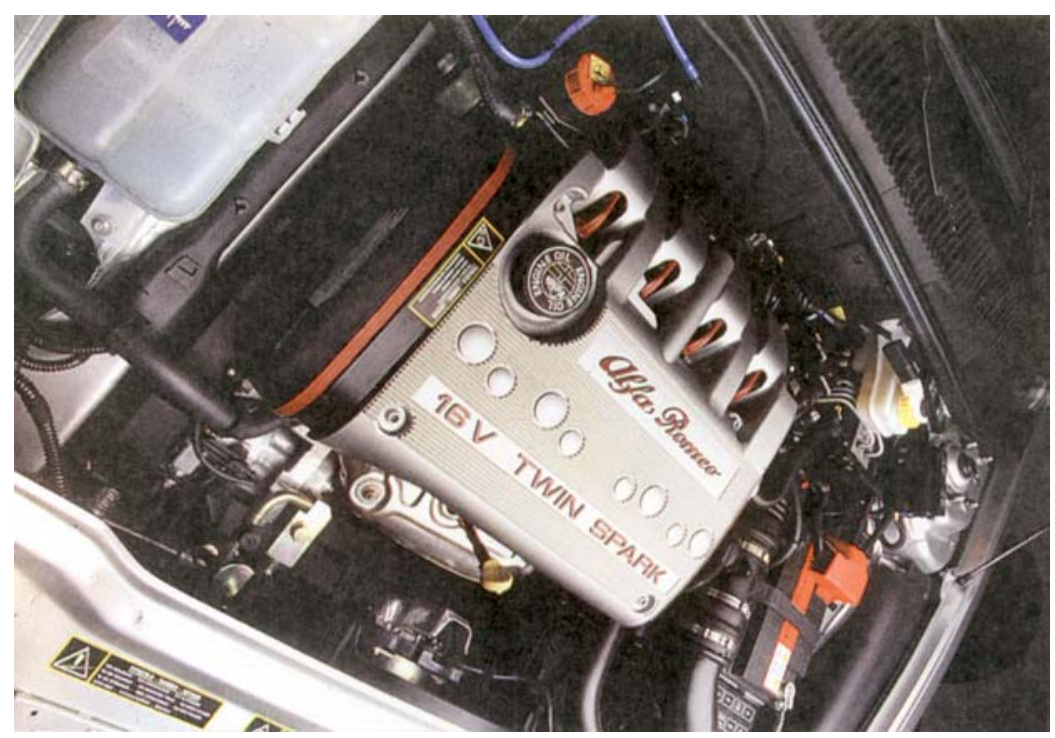

Módulo em Technyl da Rhodia Eng. Plastics utilizado no Alfa 156

trodomésticos são as novidades que a Rhodia Engineering Plastics está apresentando na Brasilplast, em seu estande localizado às ruas D-12 e E-11.

Uma das líderes mundiais no fornecimento de plásticos de engenharia, a Rhodia mostrará, no segmento da indústria automobilística, o motor do carro do ano da Europa, o Alfa 156, que tem várias peças importantes desenvolvidas em plásticos de engenharia, e os mais recentes produtos em poliamida 6 e 6.6 (náilon), especialmente desenvolvidos para a aplicação em peças técnicas como, por exemplo, circuitos de resfriamento de motores.

Para as indústrias de eletroeletrônicos e de eletrodomésticos, a Rhodia Engineering Plastics está expondo os lançamentos da linha de produtos antichama, as poliamidas 6 e 6.6 sem halógeno e sem fósforo. Estes produtos são utilizados na moldagem de carcaça para conectores e disjuntores industriais e constituem uma importante evolução em relação aos produtos antichama clássicos.

No estande da empresa, os visitantes poderão conhecer sua li- nha completa de produtos, com as marcas Technyl (poliamidas 6, 6.6 e 66/6); Techster (PBT e PBT/PET), Techtal (poliacetal), Oromid (poliamida industrial) e Amodel (poliftalamida e outros produtos da linha Amoco-USA), que têm certificações internacionais e se enquadram nos sistemas de qualidade exigidos mundialmente.

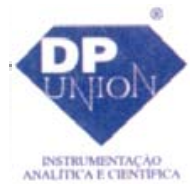

\section{Qualidade e diversidade de serviços oferecidos pela DP Union}

A DP Union Instrumentação Analítica e Científica Ltda. é uma empresa voltada para o oferecimento de serviços, atendimento e assistência técnica em produtos da mais alta tecnologia provenientes dos principais fornecedores de equipamentos de laboratório, proteção e segurança industrial. Dentre as várias empresas do exterior que representa, podem ser citadas: TA Instruments, Inc. ((ex DuPont, fornecedora de equipamentos para análise Térmica (MDSC, 
Polímeros: Ciência e Tecnologia - Jan/Mar - 99 
TGAHiRes, DMA, TMA, DEA, DTA, SDT, PDSC, etc..) e reologia)); Beckman Coulter, Inc. (analisadores de partícula); Hunterlab, Inc. (colorímetros e espectrofotômetros); Cole Parmer (com mais de 40.000 itens para laboratório); Anter Corp., (dilatômetros e condutividade térmica); Stable Micro System (texturômetros); Metrosonics (audiodosímetros); AMETEK Mansfield (bombas de amostragem de ar); BIORAD (FTIR); T M I (ensaios físicos); Holometrix, Inc. (difusividade térmica); Zeton Altamira (microrreatores).

A TA Instruments tem-se destacado pelo amplo leque de produtos para as indústrias, incluindo tanto as técnicas tradicionais quanto as especializadas, oferecendo a seus clientes uma gama de opções para os problemas na caracterização de materiais, juntamente com a habilidade para se efetuar facilmente as substituições e trocas necessárias para os sistemas. Além disso, a empresa tem dado especial atenção ao aperfeiçoamento da performance de seus equipamentos, criando o programa TA Instruments Advantage", um software desenvolvido pela Microsoft Windows que oferece facilidade no uso, versatilidade para gerar e analisar resultados, fácil interface com estação de trabalho (network) e capacidade "multitasking".

Outros equipamentos da TA Instruments colaboram também para o aumento da produtividade, como a realização de caracterização reológica completa combinando a força do Analisador Dinâmico Mecânico 2980 (com sistema de "air-bearing" incorporativo, motor sem nenhum contato, encordoamento ótico) e o Reômetro AR 1000 , o mais completo para líqui- dos viscosos e móveis, géis, pastas e sólidos. Podemos citar ainda o SDT 2960, DSC/TGA simultâneo, que combinas duas medidas termoanalíticas, oferecendo facilidade na interpretação de resultados e aumentando a produtividade a um custo atrativo, aliadas a uma excepcional sensibilidade e linha de base estável sobre uma ampla faixa de temperatura que proporcionam uma versatilidade incomparável. Outros produtos para produtividade incluem: - software para auto-análises, Rheology Navigator, DSC e TGA automatizados.

Uma recente inovação da TA Instruments é o Analisador MicroTérmico 2990, que combina a visualização por microscopia de força atômica (AMF) com a capacidade de caracterização por análise térmica. As análises microtérmicas fornecem informações similares à análise tradicional, mas em escala microscópica. Esta nova tecnologia fornece uma vasta gama de aplicações, incluindo a caracterização de fases, fibras, interfaces em polímeros, farmacêuticos e alimentos. Outras inovações incluem DSC e TGA Modulado®, TGA de alta resolu- ção e Reologia Compressional.

Os produtos são assegurados por uma completa extensão de serviços, incluindo laboratórios, publicações, cursos de treinamento, seminários, CD ROM com aplicações, Website na Internet, uma linha de telefone direta para consultas de clientes e o "homem-resposta", disponível no website ou pelo e-mail answerman@tainst.com.

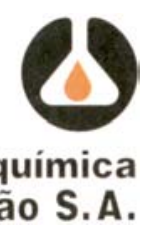

\section{PQU - Exclusividade em resinas hidrocarbônicas}

A Petroquímica União iniciou suas atividades em 15 de junho de 1972, em Santo André/SP, como o maior empreendimento do gênero na América Latina. Ao surgir como a $1^{\text {a }}$ central de matérias-primas petroquímicas do país, passou a suprir, com matéria-prima nacional, indústrias já instaladas e outras que vieram a se instalar ao seu redor.

Atenta às exigências do mercado, investiu nestes últimos 3

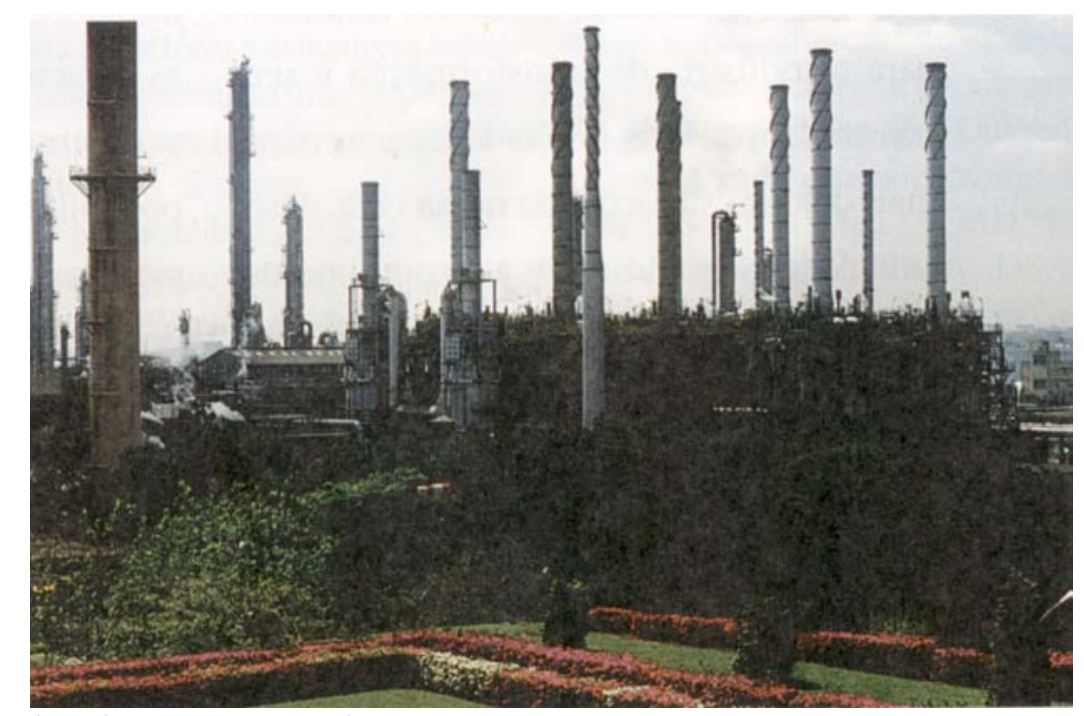

Planta da PQU em Santo André - SP 


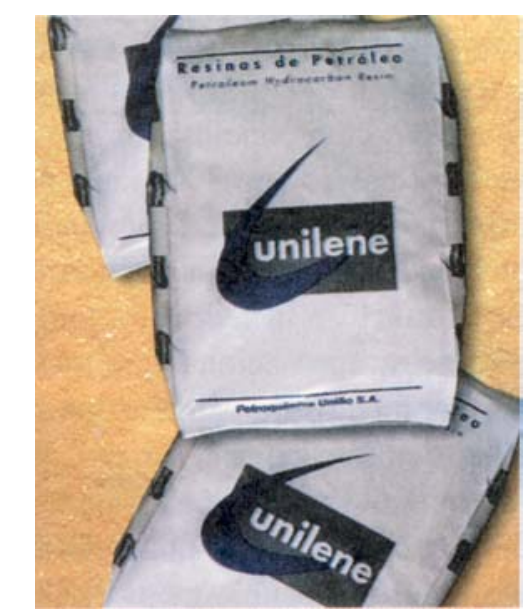

Resina Unilene

anos mais de US\$ 260 milhões em modernização, atualização tecnológica e aumento da capacidade produtiva, atingindo as atuais $500.000 \mathrm{t}$ /ano de etileno e mais de um milhão de t/ano de outros produtos petroquímicos básicos, com completa adequação aos requisitos ambientais.

O principal negócio da PQU é a produção, venda e distribuição de petroquímicos básicos, incluindo etileno, propileno grau químico e polímero, butadieno, benzeno, tolueno, xilenos e outros. Estes produtos são usados como matériaprima para a produção de petroquímicos de segunda geração, incluindo polietileno (de alta e baixa densidade), polipropileno, estireno e cumeno, que por sua vez são transformados pelas indústrias petroquímicas de terceira geração e utilizados nos diversos segmentos da economia como as indústrias automobilísticas, de embalagens, têxtil, eletroeletrônica, farmacêutica, construção civil, etc.

É a única produtora das resinas hidrocarbônicas de petróleo da América Latina, com larga aplicação nas indústrias de borracha, tintas e vernizes, tintas de impressão e adesivos. O padrão internacional de qualidade das resinas Unilene ${ }^{\circledR}$ é assegurado pelo certificado ISO 9002, concedido pela SGS-ICS.

Resinas Unilene na indústria de plásticos são resinas hidrocarbônicas aromáticas de petróleo de baixo peso molecular, obtidas pela copolimerização de estireno, indeno e seus metil derivados, contidos em uma corrente de gasolina de pirólise gerada na unidade de craqueamento de nafta da Petroquímica União. Com uma unidade em operação desde 1982, vem abastecendo não só o mercado nacional, como tem exportado para mais de 25 países de todos os continentes.

Características - As resinas Unilene são termoplásticas sólidas à temperatura ambiente e em forma de "escamas" (flakes) de cor amarelo pálido. Apresentam ponto de amolecimento que varia de 80 a $140^{\circ} \mathrm{C}$ dependendo de cada tipo de resina, e baixo índice de acidez $(<0,10)$. Apresentam compatibilidade com uma gama enorme de materiais poliméricos como:

- Elastômeros: SBR, NBR, CR, EPDM, BR, NR, TR, etc.

- Plásticos: EVA, PVC, PP, etc.

- Resinas: alquídicas, epóxi, fenólicas, estirenadas, etc.

Aplicação em plásticos: As resinas Unilene podem ser utilizadas para melhorar o processamento de EVA, PVC, e polipropileno, contribuindo para uma melhor homogeneização e coesão das cargas e demais componentes misturados à massa do polímero. Dependendo da compatibilidade com cada tipo de polímero, pode-se optar pelas séries A ou B, empregando-se até 5 partes para cada 100 do polímero a ser processado.

Vantagens técnicas: Em plásti$\cos$, as resinas Unilene proporcionam várias vantagens técnicas como: melhor resistência mecânica, melhor termoformabilidade, melhor transparência, melhor resistência à permeação de vapor de água, baixo grau de extração em NHeptano, além da facilidade de pesagem.

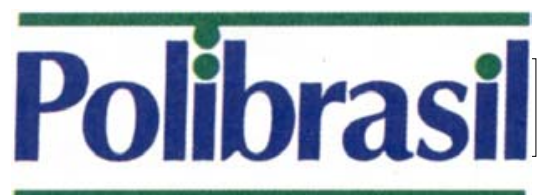

Polibrasil na última Brasilplast do século

A Polibrasill Resinas S/A, pioneira na produção de polipropileno na América Latina, estará presente na Brasilplast 99, de 8 a 13 de março, no Pavilhão de Exposições do Anhembi. A empresa estará recebendo seus clientes em um amplo estande de $230 \mathrm{~m}^{2}$, localizado à rua $\mathrm{E} \mathrm{n}^{\circ} 20$ com a rua $\mathrm{F} \mathrm{n}^{\mathrm{o}} 21$, onde fará o lançamento de cinco novos produtos:

Prolen ${ }^{\circledR}$ VS 6100 (antigo PEX 31038) - Homopolímero com distribuição normal de peso molecular, boa processabilidade a altas velocidades em fiação longa, alta taxa de estiragem e índice de Fluidez de 20,0 g/10min $(19,0$ a 24,0). Sua aplicação são os filamentos contínuos lisos ou texturizados para tapetes, carpetes, tecidos decorativos, etc.

Prolen ${ }^{\circledR}$ VS 61170R (antigo PEX -19002) - Copolímero randômico, com excelente transparência e brilho, alta fluidez, distribuição estreita de peso molecular e índice de fluidez de 21,0 g/1 $0 \mathrm{~min}(17,0$ a 24,0). É utilizado em utilidades domésticas e embalagens em geral com paredes finas. Suas vantagens são: - a maior fluidez permite injeção de peças de paredes finas com alta transparência; - baixo empenamento das peças; - ciclos de injeção menores que o Prolen ${ }^{\circledR}$ SMR 6170 Prolen ${ }^{\circledR}$ KF 6190 (antigo PEX - 
11032) - Homopolímero, com distribuição normal de peso molecular, excelente processabilidade em equipamentos de BOPP Tenter e índice de fluidez de $3,0 \mathrm{~g} / 10 \mathrm{~min}(2,5$ a 3,6$)$. Sua aplicação são os filmes de BOPP metalizados, embalagens em geral, inclusive laminados. Sua principal vantagem é a maior facilidade de impressão / metalização que o antigo Prolen ${ }^{\circledR} \mathrm{KF}$ $6190 \mathrm{H}$.

Prolen ${ }^{\circledR} X M T$ 6170P (antigo PEX -18021) - Copolímero de alta fluidez com boa resistência ao impacto para ciclo rápido de moldagem, distribuição estreita de peso molecular, com índice de fluidez $45,0 \mathrm{~g} / 10 \mathrm{~min}$ $(40,0$ a 50,0$)$. É aplicado em peças de paredes finas, utilida- des domésticas, brinquedos, móveis, tampas, etc. Suas vantagens são: - Alta fluidez para injeção de peças de paredes finas com boa resistência ao impacto; - Ciclo rápido de moldagem (inferior aos copolímeros de baixa e média fluidez); - Permite injeção de peças de maiores dimensões. Moplen ${ }^{\circledR}$ COAT EP/60 BIANCO (antigo PEX - 22013) - Copolímero de baixíssima fluidez com alta resistência ao impacto, elevada estabilização do polímero durante a extrusão, elevada estabilização anti-UV e índice de fluidez de $0,7 \mathrm{~g} / 10 \mathrm{~min}$ $(0,6$ a 0,8$)$, aplicado a revestimento de tubos metálicos. Suas principais vantagens são: - - Excelente processabilidade; - Alta

Esta matéria foi elaborada por Fátima S. Cordebello, secretária executiva da ABPol.

resistência ao impacto; - Alta resistência à indentação (perfuração/danos durante manuseio); - Alta resistência à radiação UV; - Baixa permeabilidade ao vapor d'água e baixa absorção de água.

Além desses lançamentos, será possível conhecer novas aplicações de produtos Policom e Montell. Os clientes terão, ainda, a oportunidade de navegar através de um CD-Rom, exclusivo, com os lançamentos da Montell na feira K'98, realizada em outubro de 1998, na Alemanha.

Hoje, a Polibrasil é uma das maiores produtoras de polipropileno da América Latina e, para consolidar essa posição, estará construindo uma nova planta, em Mauá/SP, com conclusão prevista para o final do ano 2000, aumentando sua capacidade de produção para 540 mil toneladas por ano. A Polibrasil é controlada pela Suzano, grupo nacional que opera nos segmentos de papel, celulose e petroquímica, e pela Montell, líder mundial na produção, comercialização e vendas de poliolefinas, materiais de tecnologia avançada e produtos correlatos, sendo o maior produtor de polipropileno do mundo. A Montell foi inicialmente formada em 1995, através da incorporação dos negócios poliolefínicos da Royal Dutch/Grupo Shell e da Montedison e, atualmente, é uma companhia da Royal Ducht/Grupo Shell. 